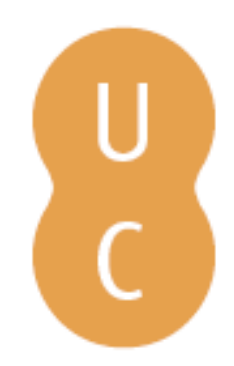

\title{
pompalina
}

\section{O Fidalgo Aprendiz no Teatro Nacional D. Maria II}
Autor(es):
Rodrigues, Maria Idalina Resina
Publicado por: Imprensa da Universidade de Coimbra; Ediciones Universidad
URL
persistente:
URI:http://hdl.handle.net/10316.2/31528
DOI:
DOI:http://dx.doi.org/10.14195/978-989-26-0245-5_16
Accessed : $\quad$ 26-Apr-2023 13:14:00

A navegação consulta e descarregamento dos títulos inseridos nas Bibliotecas Digitais UC Digitalis, UC Pombalina e UC Impactum, pressupõem a aceitação plena e sem reservas dos Termos e Condições de Uso destas Bibliotecas Digitais, disponíveis em https://digitalis.uc.pt/pt-pt/termos.

Conforme exposto nos referidos Termos e Condições de Uso, o descarregamento de títulos de acesso restrito requer uma licença válida de autorização devendo o utilizador aceder ao(s) documento(s) a partir de um endereço de IP da instituição detentora da supramencionada licença.

Ao utilizador é apenas permitido o descarregamento para uso pessoal, pelo que o emprego do(s) título(s) descarregado(s) para outro fim, designadamente comercial, carece de autorização do respetivo autor ou editor da obra.

Na medida em que todas as obras da UC Digitalis se encontram protegidas pelo Código do Direito de Autor e Direitos Conexos e demais legislação aplicável, toda a cópia, parcial ou total, deste documento, nos casos em que é legalmente admitida, deverá conter ou fazer-se acompanhar por este aviso.

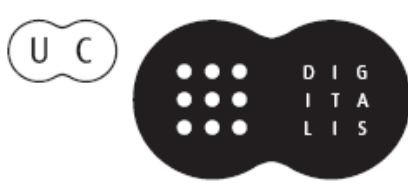


Marta Teixeira Anacleto

Sara Augusto

Zulmira Santos

Coordenação

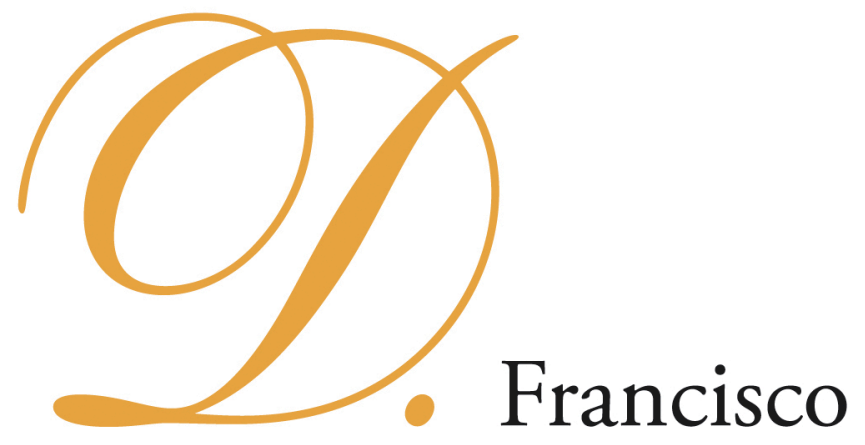

Manuel de Melo e o

Barroco Peninsular 


\title{
EDIĈ̣̃O
}

Imprensa da Universidade de Coimbra Ediciones Universidad Salamanca

\section{COORDENAÇÃo EDITORIAL}

Imprensa da Universidade de Coimbra

URL: http://www.uc.pt/imprensa_uc

Vendas online: http://www.livrariadaimprensa.com

\section{CONCEPÇÃO GRÁFICA}

António Barros

\section{REVISÃO TEXTO}

Sara Augusto

\author{
Pré-Impressão, Impressão e ACABamento \\ www.artipol.net
}

\section{IS B N}

978-989-26-0044-4 (Portugal)

978-84-7800-194-1 (Espanha)

DEPósito LEGAL

$311680 / 10$

OBRA PUBlicada COM O APOIO DE:

FCT Fundação para a Ciência e a Tecnologia

MINISTÉRIO DA CIÊNCIA, TECNOLOCIA E ENSINO SUPERIOR Portugal

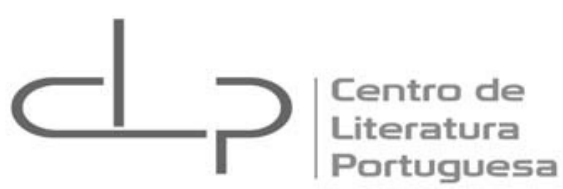

A presente publicação insere-se no Grupo "Poéticas" (coordenação de Marta Teixeira Anacleto) do Centro de Literatura Portuguesa, Unidade de I\&D financiada pela Fundação para a Ciência e a Tecnologia, ao abrigo do Programa Operacional Ciência e Inovação 2010.

(C) Agosto 2010

IMPRENSA DA UNIVERSIDADE DE COIMBRA

EDICIONES UNIVERSIDAD DE SALAMANCA 
Marta Teixeira Anacleto

Sara Augusto

Zulmira Santos

Coordenação

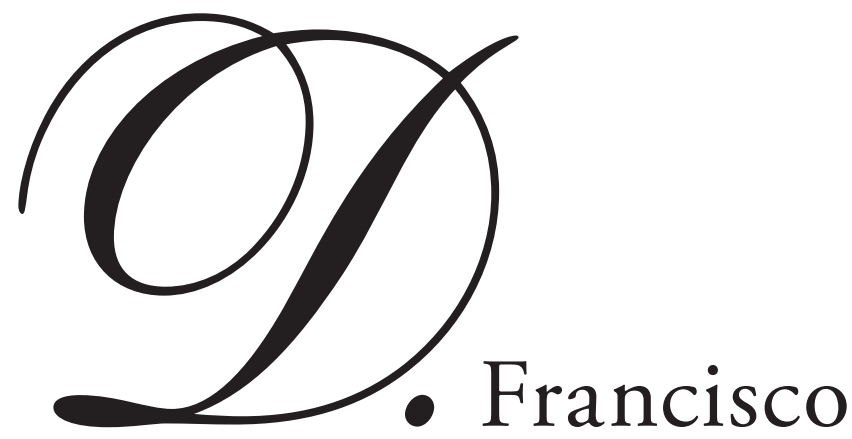

Manuel de Melo e o Barroco Peninsular

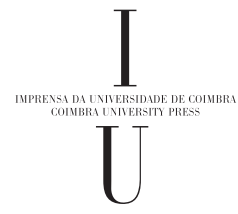


PARTE III

MODALIDADES DE ESCRITA DO BARROCO EM D. Francisco Manuel de Melo 


\section{Maria Idalina Resina Rodrigues \\ Universidade de Lisboa}

\section{O FIDALGO APRENDIZ NO TEATRO NACIONAL D. MARIA II}

Representaçôes ou adaptaçôes modernizadoras da dramaturgia clássica nacional só de vez em quando as temos; bem gostaríamos que fossem mais frequentes, porque algumas merecem inegavelmente a nossa atenção, sejam elas excelentes, boas ou medíocres; pelo que às segundas respeita, encontramo-las para todos os paladares, modelos de teatro no teatro, de cortes ou colagens, de introdução de personagens modernas num elenco antigo, de reviravoltas na linguagem, de trocadilhos críticos, de alteração de guarda-roupa e espaços, etc, etc.

No caso d'O Fidalgo Aprendiz, repetir ou refazer para o palco foi tarefa náo muito apelativa, pelo menos até ao século XX. Ignora-se, suponho que não só eu ignoro, tudo quanto a apresentaçóes nos séculos XVII, XVIII e XIX, apesar de se conhecerem ediçóes de 1665, 1676 e 1718, as duas últimas em figurino de teatro de cordel e de algumas hipóteses de utilização de uma edição de 1898, de Mendes dos Remédios.

No século passado o panorama melhorou consideravelmente: mais ediçóes, sobretudo a partir de 1943, e subidas à cena, muito provavelmente a partir de $1905^{1}$.

$\mathrm{Na}$ biblioteca do Teatro Nacional existe um exemplar manuscrito com marcas de trabalho dramatúrgico (várias indicaçóes didascálicas e algumas alteraçôes ao original, talvez com suporte na ediçáo de 1898) que me foi facultado quando pedi o texto de uma representação de 1940 , de que tinha informação segura ${ }^{2}$; ora sucede que foi ele encontrado a partir de uma ficha onde se remetia para o seu aproveitamento nas temporadas de 19041905, 1913-1914, 1930-1931, 1939-1940, 1941-1942, 1942-1943, 1943-1944, sendo que a sua datação recua realmente a 1905 .

No entanto, algumas dúvidas me ficam quanto a esquecimentos ou euforias, do mesmo modo que não posso garantir que este seja ainda este o documento que serviu de base aos espectáculos da década de quarenta (acho estranho que entretanto não tenha aparecido outra matriz para o acerto teatral).

\footnotetext{
${ }^{1}$ Sobre as edições, ler o cuidado trabalho de Evelina Verdelho, na introdução à recente edição crítica de $O$ Fidalgo Aprendiz. Coruña: Biblioteca - Arquivo Teatral Francisco Pillado Mayor, 2007.

${ }^{2}$ Agradeço esta e outras informaçốes ao Centro de Estudos de Teatro da Faculdade de Letras de Lisboa.
} 
Resta dizer que consultando a História do Teatro Nacional, de Gustavo Matos Sequeira ${ }^{3}$, encontrei registo de apresentaçóes ao público em Março de $1905^{4}$, juntamente com o Auto d'el Rei Seleuco, de 1906, em resposta a uma imposiçáo de montagem de peças de teatro clássico, e de uma alusão a um espectáculo programado para 1931, com Nascimento Fernandes no protagonista, que não chegou a ser montado porque náo houve possibilidade de «armar o cenário de Raul Lino" ${ }^{5}$ e, evidentemente, das posteriormente organizadas pela Companhia Rey Colaço - Robles Monteiro.

Não há, pois, inteira coincidência entre os informes de Matos Sequeira e os da referida ficha, mas não deixemos de registar que o autor do volume alude a "reposiçóes» diversas, sem inscrição de títulos, em 1913.

Assim sendo, e sem mais elementos, decidi-me a algumas observaçóes sobre a dita versão de 1905 que pode, ou não, ter sido aproveitada a partir de 1940, ano em que o Teatro voltou à designação primeira, depois de ter sido Almeida Garrett, desde a implantaçáo da República.

Antes, porém, facultarei uma breve listagem de outras mostras recentes da peça: 1985 no Seiva Trupe, 1987 no Teatro do Século, 1998 na Comuna, 2002 no Teatro de Portalegre, 2004 no Grupo de Teatro da Memória, e 2005 no Teatro Animação de Setúbal, em muitos casos com espectáculos oferecidos em vários pontos do país ${ }^{6}$.

Recuemos, então, agora até à primeira metade do século XX e retenhamos algumas linhas do leve trabalho para cena (não se trata de uma adaptação) do legado de D. Francisco Manuel de Melo.

As indicaçôes de espaços multiplicam-se, as de vestuário restringem-se ou diferenciamse no sentido da simplificação, afastando-se ligeiramente das seiscentistas.

Algumas alteraçóes parecem acentuar o lado cómico, como, por exemplo, a substituição de Mestre Jacques por Mestre Esfola ${ }^{7}$, a invenção de D. Gil para náo confessar a falta de um coche ( $\left(\mathrm{Oh}\right.$ ! Emprestei-o a El-Rei» $\left.{ }^{8}\right)$, a risota de Afonso e Beltrâo perante os medos nocturnos do fidalgo, a troca de "fato" por "consciência»", a mudança de resposta a uma questão sobre onde se encontram («são») os criados: de «todos são dos seus logares» passa-se a «são donde foram nascidos» ${ }^{10}$.

Relativamente a cortes, e para além de alguns cujo significado não fui capaz de detectar (por exemplo, uma referência a Dom Sebastião nas várias ediçóes consultadas), um me

\footnotetext{
${ }^{3}$ Gustavo de Matos Sequeira, História do Teatro Nacional D. Maria II, II volume. Publicação comemorativa do centenário 1846 - 1946. Lisboa: 1955.

${ }^{4}$ Gustavo de Matos Sequeira, História do Teatro Nacional, p. 449.

5 Gustavo de Matos Sequeira, História do Teatro Nacional, p. 665.

${ }^{6}$ Houvera anteriormente uma adaptação de António Manuel Couto Viana, editada em 1955 e incluída em Peças de Teatro, da responsabilidade de J. A. Ribeiro, que percorreu o país no âmbito de uma Campanha Nacional de Educação de Adultos.

${ }^{7}$ D. Francisco Manoel, O Fidalgo Aprendiz, Farça em 3 jornadas, 1905, texto manuscrito, 6v; o confronto é feito com a edição de Mendes dos Remédios. Coimbra: França Amado, 1898, p. 14.

${ }^{8}$ O Fidalgo Aprendiz, texto manuscrito, fl. $11 \mathrm{v}$.

${ }^{9}$ O Fidalgo Aprendiz, texto manuscrito, fl. 2; edição de Mendes dos Remédios, p. 5.

${ }^{10}$ O Fidalgo Aprendiz, texto manuscrito, fl. 3; edição de Mendes dos Remédios, p. 8.
} 
parece significativo de bom entendimento da reacção do público. A segunda jornada termina com a partida de D. Gil de junto de Brites, esquecendo o talvez desnecessário diálogo entre a jovem e a mãe.

Consultando os programas dos três espectáculos da década de quarenta, recolhemos no primeiro, para além dum juízo de valor («um dos documentos mais curiosos da literatura dramática portuguesa») ${ }^{11}$, a informação de que com esta farsa se representou o auto do Filodemo. Pelo de 1944, ficamos a saber que a exibição preencheu a primeira parte de uma récita clássica de um ciclo cultural, cuja segunda parte contou com $A$ Visita das Fontes, com excertos do Padre António Vieira, com cantigas e com a declamação de um soneto, aparecendo a de 1943 apenas como uma reposição.

De 40 para 44 foram mínimas as alterações no elenco (João Villaret, Lucília Simóes e Maria Lalande, entre outros, permanecem, sai Estêvão Amarante). Com mínimas alteraçóes no elenco, o natural é que o texto base tenha sido o mesmo.

Fica ainda a informação de que estes espectáculos se inserem numa década em que o Teatro D. Maria apostou fortemente num reportório nacional, com especial atenção a Gil Vicente que, como sabemos, mereceu cenários e figurinos de Almada Negreiros.

Assim reza a introdução de Vítor Pavão dos Santos ao minucioso catálogo intitulado $A$ Companhia Rey. Colaço. Robles. Monteiro (1921-1974):

De facto, neste período admirável de ressurgimento da dramaturgia portuguesa, são levadas à cena 116 peças de autores nacionais, 63 em estreia absoluta, incluindo dez revistas de Carnaval e quatro peças infantis.

(...)

Foi uma época prodigiosa, em que uma geração privilegiada de espectadores pôde tomar contacto com os seus clássicos, vivos no palco. Como nunca acontecera antes. Como nunca viria a acontecer depois. ${ }^{12}$

Esboçadas estas breves incursóes de D. Francisco na sala grande do D. Maria, passemos, então, às esperadas modificações de 1988.

Os dez anos da reabertura do teatro depois do grande incêndio de 1964 foram assinalados com a apresentação de diversas peças estrangeiras seguidas da Trilogia Portuguesa de Miguel Rovisco, o jovem dramaturgo que se suicidara no ano anterior, e de $O$ Fidalgo Aprendiz, que veio a fechar a temporada de 1987-1988, com encenação de Varela Silva, figurinos de Octávio Clérigo e música de Fernando Guerra.

A informação do adaptador, Norberto Barroca ${ }^{13}$, é a seguinte:

${ }^{11}$ Programa do espectáculo.

${ }^{12}$ Vítor Pavão dos Santos, A Companhia Rey. Colaço. Robles. Monteiro, (1921 - 1974), catálogo coordenado por Margarida Palhinha. Lisboa: Secretaria de Estado da Cultura/Instituto Português do Património Cultural/Museu Nacional do Teatro, 1987, p. 5.

${ }^{13}$ Norberto Barroca já fora responsável pela adaptação apresentada pelo Seiva Trupe. 
O texto original foi reformulado no que diz respeito a expressóes e formas gramaticais em desuso, sem que o seu conteúdo fosse alterado e manteve-se o verso e a consonância da rima. $^{14}$

Prevista a estreia para imediatamente a seguir aos feriados de Junho, a adaptação só chegou aos espectadores no dia 22, mantendo-se em cartaz até 31 de Julho e sendo recuperada de 21 de Outubro a 6 de Novembro. O atraso ficou a dever-se a uma greve dos trabalhadores que os jornais da época referem, e foi antecedida de uma ida ao Parlamento e de protestos de vária ordem:

Artistas do Teatro Nacional D. Maria II deslocaram-se ontem à Assembleia da República, com o objectivo de entregarem aos deputados um «dossier» relativo à situação actualmente vivida naquele teatro, em geral as condiçôes de trabalho e salariais». ${ }^{15}$

Os ajustamentos, um pouco na linha do teatro no teatro, incorporam-se, de facto, em todo o auto do qual respeitam relativamente a versificação, a divisão em três jornadas, embora repartidas por cenas, a unidade de acção e até a contenção num só dia do argumento; o vocabulário é, porém, actualizado com muita (demasiada?) frequência, o mesmo sucedendo a expressóes feitas, há alguns cortes e acrescentos; o cenário principal concentranos no Rossio de hoje onde será montado um estrado.

Tendo apenas em conta o que a D. Francisco Manuel de Melo competia e Barroca modificou, registemos dois ou três exemplos avulsos de pequenas emendas.

Escrevera D. Francisco:

Sou velho, já fui mancebo, cousa que, mal que lhes pês, virá por vossas mercês;

Naci no lugar do Sebo faz hoje setenta e três. ${ }^{16}$

Altera o texto moderno:

Sou velho, já fui mancebo, coisa que, mesmo sem querer, vos virá a acontecer.

\footnotetext{
${ }^{14}$ Programa do espectáculo, p. 11.

${ }^{15}$ Diário de Notícias, 20 de Maio de 1988.

${ }^{16} \mathrm{O}$ confronto, uma vez que não parece aceitável que Barroca tenha recorrido à edição de 1898, faz-se agora com a recente edição de Evelina Verdelho, o que se justifica por não se saber qual a edição base e por se ter verificado na análise de várias ediçóes que o que fundamentalmente muda é a ortografia e não o vocabulário; os versos transcritos encontram-se na página 105 , mas a editora moderna opta por «Lagar» em vez de «lugar», dando as suas razóes.
} 
Nasci no lugar do Sebo

a idade não sei dizer. ${ }^{17}$

Comunica-nos o aio Afonso Mendes no original:

Vi el-rei D. Sebastião. ${ }^{18}$

Escreve o adaptador:

Vi el-rei D. Sebastiáo.

Vi depois de sessent' anos

chegar a Restauração

e no trono o rei D. João. ${ }^{19}$

Ou ainda:

Isso sim, é o que importa

ser ginete e ser sendeiro. ${ }^{20}$

Versos trocados por:

Isso, sim, é o que importa

ser para toda a obra obreiro. ${ }^{21}$

O mais significativo na obra preparada em 1988 não tem, porém, que ver com estas modificaçóes pontuais porque, de facto, a principal estratégia do autor moderno consiste nos longos acrescentamentos que actualizam a problemática (o tempo passou, os homens não mudaram) ou indiciam um especial didactismo no dar a conhecer situaçóes da vida de D. Francisco ou da história da dramaturgia nos séculos XVI e XVII.

Acompanhemos, pois, toda a versão, não sem lembrar que nela participaram actores como Raul Solnado (primeira actuação no D. Maria) ${ }^{22}$, na personagem de Gil Cogominho, Rui de Carvalho, como D. Francisco Manuel de Melo e Fernanda Borsatti, como Isabel.

A enquadrar o auto há um prólogo e um epílogo.

No prólogo poderemos considerar duas partes: na primeira, cruzamo-nos com D. Francisco Manuel na prisão da Torre de Belém; escreve a D. João IV clamando a sua

\footnotetext{
${ }^{17}$ O Fidalgo Aprendiz, texto dactilografado, pp. 1-2.

${ }^{18}$ O Fidalgo Aprendiz, edição de Evelina Verdelho, p. 106.

${ }^{19}$ O Fidalgo Aprendiz, texto dactilografado, p. 2.

${ }^{20}$ O Fidalgo Aprendiz, edição de Evelina Verdelho, p. 111.

${ }^{21}$ O Fidalgo Aprendiz, texto dactilografado, p. 6.

${ }^{22}$ Raul Solnado tinha representado o papel de Mestre de dança na Sociedade Guilherme Cossul. Informação em Leonor Xavier, Raul Solnado. A vida não se perdeu. Lisboa: Oficina do Livro, 2003, p. 272.
} 
inocência e refresca para o público alguns passos da sua vida e dos seus conhecimentos dramático-literários (Lope, Tirso, Calderón, entre outros); clarificado fica ainda o seu intento de escrever uma comédia à portuguesa; na segunda parte, um grupo de actores com nomes de personagens vicentinas (Inês Pereira, Mofina Mendes, Aires Rosado e outras) repentinamente caídos em pleno século XX manifestam o seu desejo de representar uma peça, passam em revista modelos do teatro europeu e espaços de representação, acabando por eleger como uma das melhores comédias nacionais O Fidalgo Aprendiz, evidentemente, cujo protagonista lhes aparece como "a imagem de Portugal»" semelhança esta que frequentemente virá a ser reforçada em posteriores dizeres.

«É um fidalgo pobre como Portugal» insistirá o mesmo interveniente ${ }^{24}$.

De seguida, muitas questóes e longas respostas se incorporam, antes de mais, no decurso das liçóes dos Mestres (de esgrima, de dança e de poesia), em diálogos entre eles e o discípulo que transferem para a modernidade os questionáveis desejos de D. Gil.

Ouçamos um pouco do que, em pleno século XX, ele aprende do Mestre de esgrima:

MESTRE ESGRIMA

A arma para vencer

hoje em dia, é o dinheiro.

Fazer jogo financeiro,

e esgrimir com saber...

DOM GIL

E como devo fazer?

MESTRE ESGRIMA

Lutai com cabeça e siso!

E reparai que este aviso

nunca deveis esquecer:

Nunca deis nada a ninguém

e 'sgrimi c'os dedos todos.

E sempre com mui bons modos

embolsai o que convém.

DOM GIL

Mas não quero "pé de meia», já estou farto de poupar.

Quero na bolsa jogar

e ter sempre a bolsa cheia.

MESTRE ESGRIMA

Com arte deveis lutar, que é golpe de economia,

\footnotetext{
${ }^{23}$ O Fidalgo Aprendiz, texto dactilografado, p. 11.

${ }^{24}$ O Fidalgo Aprendiz, texto dactilografado, p. 12.
} 
atenção à mais valia

e ao 'scudo a flutuar;

ao oscilar cambial,

à galopante inflacção,

à fiscal contribuição

e à crise conjuntural. ${ }^{25}$

De seguida, um troço da animada conversa com o Mestre de dança:

\section{DOM GIL}

Pois sois Mestre mui minguado.

$\mathrm{O}$ que queria, de momento,

era outra dança, moderna.

Quero saber dar à perna

p'ra dançar no Parlamento.

MESTRE DANÇA

Quereis nas Côrtes dançar?

\section{DOM GIL}

Queria ser deputado, ser dançador afamado

para saber legislar.

MESTRE DANÇA

Esse é bailado eloquente!

DOM GIL

Mas já os vi a dançar

o vira. Pois a virar

estão eles constantemente. ${ }^{26}$

E, por fim, o que D. Gil confessa ao Poeta:

\section{POETA}

O que quereis, afinal?

$\mathrm{O}$ que vos posso ensinar

se vós já sabeis trovar?

DOM GIL

Queria ser intelectual!

Desses que sabem falar, mas ninguém os compreende; escrevem e ninguém os entende, mas 'screvem p'ra comunicar.

\footnotetext{
${ }^{25}$ O Fidalgo Aprendiz, texto dactilografado, pp. 13-14.

${ }^{26}$ O Fidalgo Aprendiz, texto dactilografado, p. 26.
} 
Desses que deixam mensagem;

e que falam p'rós jornais;

passam férias em Cascais

e andam sempre em viagem.

Desses cultos, eruditos,

que escrevem com conteúdo

sobre nada e sobre tudo,

com transcendentes conflitos. ${ }^{27}$

No entanto, outras expansões merecem sinalizadas: os comentários irónicos dos actores, no final das jornadas, o diálogo entre Brites e D. Gil, no encontro em casa desta, o prolongamento do posterior monólogo do protagonista, durante a noite, a caminho da rua de Isabel e, como atrás se adiantou, um epílogo, tal como o prólogo, inteiramente original.

Alguns versos das falas no encontro com a interesseira Brites:

DOM GIL

Ó meu Anjo e meu requebro!...

Se a cega fosseis vós,

eu era o guia!

BRITES

Tendes casa?

DOM GIL

Em Cascais!

BRITES

Tem piscina?

DOM GIL

Um oceano!

BRITES

E jardim?

DOM GIL

São todos municipais! ${ }^{28}$

Por sua vez, no epílogo de 55 versos, participam o grupo de actores, as figuras de Isabel, de Afonso e de D. Gil, em falas individualizadas, e todos em conjunto num final apoteótico:

\footnotetext{
${ }^{27}$ O Fidalgo Aprendiz, texto dactilografado, p. 37.

${ }^{28}$ O Fidalgo Aprendiz, texto dactilografado, p. 54.
} 


\section{TODOS}

Há muito quem queira ser na sociedade aprendiz

e anda metendo o nariz em tudo o que bem parecer.

Sempre houve neste país

o desejo de parecer

ter grandezas, ter saber,

sem se passar de aprendiz.

O tempo é que é juiz

que vem mostrar cedo ou tarde

que quem mais fizer alarde

não passa dum aprendiz.

Quando se quebra o verniz

a um chefe dirigente

vê-se logo de repente

que não passa de aprendiz.

Mesmo quem diz ser feliz,

de virtudes soberano,

nesta comédia de engano

náo passa dum aprendiz.

E p'ró final ser feliz

aquilo que se deseja

é que nenhum de vós seja

mais um Fidalgo Aprendiz. ${ }^{29}$

Assim esboçado o encadeamento de sequências desta actualização, façamos, então, saber que o espectáculo foi simultaneamente um estrondoso êxito de bilheteira e... um convite ao zurzir da crítica, crítica que, é preciso dizê-lo, não atinge tanto o texto quanto as outras componentes do espectáculo teatral (marcação de palco, recursos cénicos, critério usado na direcção de actores).

Abrangendo o que se considerou ser uma temporada "catastrófica», Fernando Midóes escreve em 1 de Julho que a única nota positiva de todo o espectáculo iria para o trabalho de actor de Manuel Coelho, o Mestre de dança ${ }^{30}$. E regressando ao assunto, em 20 de Setembro, afirma que o D. Maria fechou a temporada com «chave de lata», com uma «mistela» que, "querendo evidenciar o protagonista, afundou-o e este náo teve talento para se salvar a nado» ${ }^{31}$.

\footnotetext{
${ }^{29}$ O Fidalgo Aprendiz, texto dactilografado, p. 97. Na adaptação da Comuna repete-se este conjunto de estrofes.

${ }^{30}$ Diário Popular, 1 de Julho de 1988.

${ }^{31}$ Diário Popular, 20 de Setembro de 1988.
} 
Quanto a Lúcia Sigalho termina ela praticamente um artigo no Tempo de 7 de Julho com um desolado conselho: «Esta peça é a evitar»" ${ }^{32}$.

No entanto, embora as mais acutilantes censuras dos entendidos incidam sobre as vertentes não textuais, a verdade é que o resultado desta re-escrita do Fidalgo me merece algumas consideraçóes, particularmente no que aos espraiados embrechamentos diz respeito.

$\mathrm{Na}$ primeira jornada as intervençóes dos Mestres no diálogo com o pupilo pouco menos espaço ocupam do que aquele que é deixado para as falas seiscentistas; um bom exemplo é o do Mestre de esgrima que, enquanto aguarda o começo da lição, se derrama por mais de vinte estrofes, número bem superior ao das originais que as antecedem e ao das que se lhes seguem.

Ainda que mais comedidos, também os outros dois Mestres de 1988 debitam, antes da saída de cena, um conjunto de versos equivalente ao que recolhem de 1665 .

Complementarmente, como a atitude crítica que estes desenvolvimentos supóem incide em aproximadas zonas dos males do Portugal da época, não só se arriscam elas a uma função de quase reforço, como aproximam os modos de falar das personagens, assim cortando a diversidade original, tanto mais que muito menos se prestam a gestos identificativos da matéria das explicaçóes.

Além disso, dilatam excessivamente a primeira jornada, já de si razoavelmente extensa nas ediçóes da farsa, com a agravante de secundarizarem as restantes onde a intriga, de facto, se desenrola e as réplicas se agilizam.

Náo pode igualmente ficar sem uma referência menos positiva o aparecimento de figuras vicentinas, nomes bem conhecidos dos espectadores, a pronunciarem falas estranhas ao seu perfil original, retiradas de autores vários, mais antigos ou mais modernos, não importa. Não se atinge assim, relativamente a elas, o impacto didáctico que o adaptador parece ter desejado desde a sua introdução.

Por fim, e reconhecendo a subjectividade da afirmação, julgo que a parcela de ternura que o fidalgo nos poderia merecer ao recordar com amizade Afonso Mendes e D. Beltrão, afinal os seus traidores, se esbate no cantar final que, uma vez mais, o ridiculariza.

Se as outras modernas apropriaçóes atrás elencadas foram, ou não, textualmente mais convincentes, não o sei dizer, porque, apesar das tentativas feitas, não tive possibilidade de as percorrer; com pareceres de especialistas também me não confrontei, porque eles rarearam nas publicaçóes consultadas.

Uma só excepção encorajadora para os esforços modernizadores d' O Fidalgo Aprendiz nos trazem alguns excertos de críticas ao espectáculo da Comuna, de 1998:

[Peça] cheia de enxertos engraçados ora actualizando o português, ora piscando o olho à actuali-dade política, recuperou a rábula revisteira....Ao nível do melhor do que a Comuna tem feito. ${ }^{33}$

Bem humorado e actualizado... Cheio de mensagens e com destinatário. ${ }^{34}$

Pequena obra-prima do humor burlesco. ${ }^{35}$

\footnotetext{
${ }^{32}$ Tempo, 7 de Julho de 1988.

33 Público, 13 de Julho de 1998.

${ }^{34}$ Expresso, 18 de Julho de 1998.
} 
Trar-nos-á o ano do centenário alguma boa notícia? Seria bom...

${ }^{35}$ Público, 9 de Outubro de 1998. 
Série

Documentos

Imprensa da Universidade de Coimbra

Coimbra University Press

2010

- U

C • 